\title{
Süper Ligde Mücadele Eden A Takım ve U21 Ligi Futbolcularının Mevkilere Göre Maksimal Oksijen Tüketimi Değerlerinin İncelenmesi
}

\author{
Sinan SEYHAN
}

Manisa Celal Bayar Üniversitesi Spor Bilimleri Fakültesi, MANISA

Künye: Seyhan, S. (2018). Süper Ligde Mücadele Eden A Takım ve U21 Ligi Futbolcularının Mevkilere Göre Maksimal Oksijen Tüketimi Değerlerinin İncelenmesi. Gaziantep Üniversitesi Spor Bilimleri Dergisi 3(2): 24-34.

\section{Öz}

Çalışmanın amacı Türkiye Futbol Federasyonu (TFF) Spor Toto Süper Lig İlhan Cavcav Sezonunda mücadele eden bir takım ( $n=21)$ ile aynı takımın U21 Ligi altyapı oyuncularının $(n=21)$, Yo-Yo aralıklı toparlanma seviye 1 (Yo-Yo IR1) testinden elde edilen maksimal oksijen tüketimi $\left(\mathrm{VO}_{2 \text { maks }}\right)$ değerlerinin mevkilere göre incelenmesidir. Bu çalışmaya 16-32 yaşları arasında toplam 42 futbolcu gönüllü olarak katılmıştır. Futbolculara standart ölçülerdeki futbol sahasında Yo-Yo IR1 testi uygulanmış ve futbolcuların koşu mesafeleri hesaplanarak elde edilen veriler doğrultusunda bireysel $\mathrm{VO}_{2 \text { maks }}$ değerleri belirlenmiştir. Verilerin istatistiksel analizinde SPSS.21 paket programı kullanılarak, futbolcuların mevkilerine ilişkin tanımlayıcı analizleri ortalama ve standart sapma olarak hesaplanmıştır. Futbolcuların mevkilere göre $\mathrm{VO}_{2 \text { maks }}$ değerleri arasındaki farklar Bağımsız İki Örnek T testi ile test edilmiştir. Anlamlıık düzeyi $p<0,05$ olarak alınmıştır. Elde edilen bulgulara göre; A takımda oynayan futbolcuların oynadıkları mevkilere göre koşu mesafeleri sırasıyla kaleci, savunma, orta saha ve hücum pozisyonları için: $1747 \pm 83,3$ m.; $2526 \pm 283,3$ m.; $2600 \pm 313,9$ m.; $2368 \pm 175,3 \mathrm{~m}$. olarak tespit edilmiştir. Aynı takımın U21 ligi futbolcularının mevkilere göre kat ettikleri mesafe: $1253,3 \pm 122,2$ m.; $1649 \pm 129,3$ m.; $1752 \pm 400$ m.; $1800 \pm 73$ m. olarak belirlenmiştir. Ayrıca bu mesafelere karşılık gelen $\mathrm{VO}_{2 \text { maks }}$ değerleri sırasıyla oynadıkları mevkilere göre $A$ takım için; $50,9 \pm 1 \mathrm{ml} \cdot \mathrm{dk}^{-1} \cdot \mathrm{kg}^{-1} ; 57,6 \pm 2,4 \mathrm{ml} \cdot \mathrm{dk}^{-1} \cdot \mathrm{kg}^{-1} ; 58,2 \pm 2,67 \mathrm{ml} \cdot \mathrm{dk}^{-1} \cdot \mathrm{kg}^{-1} ; 56,22 \pm 1,47 \mathrm{ml} \cdot \mathrm{dk}^{-1} \cdot \mathrm{kg}^{-1}$ olarak tespit edilmiştir. Aynı takımın U21 ligi futbolcularının koştukları mesafelere karşılık gelen $\mathrm{VO}_{2 m a k s}$ değerleri sırasıyla oynadıkları mevkilere göre: $46,9 \pm 1,01 \mathrm{ml} \cdot \mathrm{dk}^{-1} \cdot \mathrm{kg}^{-1} ; 50,2 \pm 1,09 \mathrm{ml} \cdot \mathrm{dk}^{-1} \cdot \mathrm{kg}^{-1}$; $51,7 \pm 2,04 \mathrm{ml} \cdot \mathrm{dk}^{-1} \cdot \mathrm{kg}^{-1} ; 51,5 \pm 0,6 \mathrm{ml} \cdot \mathrm{dk}^{-1} \cdot \mathrm{kg}^{-1}$ olarak belirlenmiştir. Oyun mevkilerine göre yapılan karşılaştırmalarda $\mathrm{VO}_{2 \text { maks }}$ değerlerinin A takımda, U21 takımına oranla anlamlı düzeyde daha büyük $(p<0,05)$ olduğu görülmüştür. Sonuç olarak, profesyonel futbolcuların aerobik güç performans değerlerinin oynadıkları mevkilere göre farklılık gösterdiği tespit edilmiştir. Ayrıca antrenörlerin bu farklılıkları bilmesi ve buna uygun antrenman programı hazırlaması futbolcu performanslarında bir artışı beraberinde getirecektir.

Anahtar Sözcükler: Futbol, Dayanıklılık, Yo-Yo

\section{Orijinal Makale}

\section{Yayın Bilgileri}

Gönderi Tarihi: 02.04.2018

Kabul Tarihi: 17.05.2018

Yayın Tarihi: 20.06.2018

\section{Sorumlu Yazar}

e-mail: sinanseyhan@gmail.com

DOI: 10.31680 /gaunjss.411945

\section{The Examination of Maximal Oxygen Consumption Values of Various Play Position Super League and U21 Football Players}

\begin{abstract}
The aim of this study was to examine the results of different play position player's maximal oxygen consumption $\left(\mathrm{VO}_{2 \max }\right)$ tests obtained from intermittent recovery level 1 (Yo-Yo IR1). Participating two teams were a Sports Toto Super League participant A team $(n=21)$ and a U21 $(n=21)$ team of the same club. A total of 42 football players between the ages of 16-32 volunteered in the study. Players participated in Yo-Yo IR1 test on a soccer field and the individual $\mathrm{VO}_{2 \max }$ data was obtained by calculating the running distances of the soccer players. In the statistical analysis of the data SPSS.21 package program was used. Descriptive analyzes of the football players positions were calculated and mean and standard deviation were examined. The differences between the $\mathrm{VO}_{2 \max }$ values according to the soccer player's positions were tested by two Independent Sample T tests. Significance level was taken as $\mathrm{p}<0.05$. The running distance results for goalkeeper, defense, midfield and offensive positions of team A were $1747 \pm 83.3 \mathrm{~m} .2526+-283.3 \mathrm{~m}$.; $2600+-313.9$ $\mathrm{m}$.; $2368 \pm 175.3 \mathrm{~m}$. respectively. The running distance results for goalkeeper, defense, midfield and offensive positions of team U21 were $1253.3 \pm 122.2 \mathrm{~m}$.; $1649+-129.3 \mathrm{~m}$.; $1752 \pm 400 \mathrm{~m}$; $1800 \pm 73 \mathrm{~m}$. respectively. In addition, $\mathrm{VO}_{2 \max }$ values for the $\mathrm{A}$ team according to the positions were $50.9 \pm 1 \mathrm{ml} \cdot \mathrm{dk}^{-1} \cdot \mathrm{kg}^{-1} ; 57.6 \pm 2.4 \mathrm{ml} \cdot \mathrm{dk}^{-1} \cdot \mathrm{kg}^{-1} ; 58.2 \pm 2.67 \mathrm{ml} \cdot \mathrm{dk}^{-1} \cdot \mathrm{kg}^{-1} ; 56.22 \pm 1,47 \mathrm{ml} \cdot \mathrm{dk}^{-1} \cdot$ $\mathrm{kg}^{-1}$ respectively. The $\mathrm{VO}_{2 \max }$ values for the U21 team according to the positions were $46.9 \pm 1.01$ $\mathrm{ml} \cdot \mathrm{dk}^{-1} \cdot \mathrm{kg}^{-1}, 50.2 \pm 1.09 \mathrm{ml} \cdot \mathrm{dk}^{-1} \cdot \mathrm{kg}^{-1} ; 51.7 \pm 2.04 \mathrm{ml} \cdot \mathrm{dk}^{-1} \cdot \mathrm{kg}^{-1} ; 51.5 \pm 0.6 \mathrm{ml} \cdot \mathrm{dk}^{-1} \cdot \mathrm{kg}^{-1}$ respectively. $\mathrm{VO}_{2 \max }$ values were significantly higher $(p<0.05)$ in $\mathrm{A}$ team. As a result, it has been found that the aerobic power performance values of professional soccer players differ according to the position they play. Knowledge of these differences may aid the coaches to prepare appropriate training programs and provide increase in football players' performances.
\end{abstract}

\section{Original Article}

Article Info

Received: 02.04.2018 Accepted: 17.05 .2018 Published: 20.06.2018

Corresponding Author e-mail: sinanseyhan@gmail.com 


\section{Giriş}

Futbol günümüzde 120 bin lisanslı oyuncusu ve 400 milyar dolarlık bütçesi ile dünyanın en popüler sporu konumundadır. Yıllardır futbol oyunun daha iyi nasıl oynanacağı, daha yüksek performansa nasıl ulaşılacağı ile ilgili çok sayıda araştırma yapılmıştır. Bu araştırmalar içerisinde fiziksel performans, teknik-taktik analizler, psikolojik, sosyolojik ve ekonomik değerlendirmeler yapılmaktadır. Oyuncuların yüksek performans düzeylerine ulaşabilmesi için yapılmış olan çalışmalarda futbolcuların başarılı olabilmelerinin; yetenek, dayanıklılık, kuvvet, sürat, esneklik, koordinasyon, hareketlilik, motivasyon ve teknik-taktik yeterliliklerin eğitimine ve gelişimine bağlı olduğu görülmektedir (Ak, 2010).

Dayanıklılık gerektiren diğer spor branşlarında olduğu gibi futbolda da sporcunun performansını uzun süre devam ettirebilmesi önemlidir. Yüksek şiddetli bir egzersizde kas hücresinin aerobik yolla enerji üretebilme yetisi olarak ifade edilen aerobik güç, $\mathrm{VO}_{2 m a k s}$ ile tanımlanır. Aerobik kapasite ise dayanıklılık kelimesi ile eş anlamlı olarak kullanılır ve bir egzersiz aynı şiddette uzun süre sürdürebilme özelliğidir (Aşçı, 2008). Aerobik kapasitenin önemli olduğu sporlarda $\mathrm{VO}_{2 m a k s}$ performansı belirlemede önemli bir parametre olmakla beraber bu değerlerin bilinmesi hem sporcu hem de antrenörler için önemlidir (Svensson, Drust 2005). Literatürde bir futbol müsabakasında, 90 dakika boyunca futbolcuların sarf ettikleri hareketlerin \%90'ını aerobik, \%8,6'sı da anaerobik olarak gerçekleştiği ifade edilmiştir (Bangsbo, Norregaard ve Thorsoe 1991). Bu da aerobik kapasitenin önemli olduğu futbolda, futbolculara aerobik kapasiteyi artıracak antrenman modellerinin uygulanması bireysel olarak futbolcuların performanslarında bir yükselişi beraberinde getirmektedir. Nitekim performans artışı ile ilgili yapılan bir çalışmada bir futbol maçında futbolcuların $\mathrm{VO}_{2 m a k s}$ değerlerinde \%11'lik bir artışın görülmesi bu futbolcuların $1800 \mathrm{~m}$ daha fazla koştuğu bildirilmiştir (Chamari ve diğerleri, 2004). Sporcuların bireysel performanslarını zorladığı aktiviteleri üst düzeyde yapabilmeleri, kondisyon düzeylerinin iyi olması ile mümkündür. $\mathrm{Bu}$ nedenle $\mathrm{VO}_{2 m a k s}$ kişinin kondisyon düzeyini gösteren en iyi kriter olarak kabul edilmektedir (Ünal ve diğerleri, 2001). Futbol araştırmalarında ölçülen en yüksek $\mathrm{VO}_{2 \text { maks }} 80 \mathrm{ml} \cdot \mathrm{dk}^{-1} \cdot \mathrm{kg}^{-1}$ olmakla beraber, kaleciler hariç erkek futbolcularda ortalama olarak $55-68 \mathrm{ml} \cdot \mathrm{dk}^{-1} \cdot \mathrm{kg}^{-}$ ${ }^{1}$ oranında olduğu belirtilmektedir (Aşçı 2008).

Futbolda antrenmanın türü, süresi, tekrarları ve şiddeti sporcunun performansının yükselmesinde en önemli faktörlerdir. Futbolda, sezon başında ya da 
sezon içinde antrenman programı yapılırken her sporcunun fiziksel ve fizyolojik özellikleri göz önünde bulundurulmalıdır. Bu yüzden dayanıklılık testlerinden biri olan Yo-Yo IR1 testi hem oyuncunun performans düzeyinin değerlendirilmesinde hem de antrenman planlamasında antrenörlere futbolcunun hazır olup olmadığı hakkında bilgi verir. Aynı zamanda bu testten elde edilen veriler futbol maçında gösterilen diğer fiziksel performans değerleriyle de ilişkilidir. Bu da Yo-Yo IR1'den elde edilecek verilerin futbolcuların maç performanslarını değerlendirmede güvenilir ve geçerli bir ölçüm olduğunu göstermektedir (Castagna ve diğerleri 2009; Castagna ve diğerleri, 2010; Krustrup ve diğerleri, 2003). Bunun yanı sıra Yo-Yo IR1'den elde edilecek verilerin futbolda oyunculara verilen görev farklılıkları ile fiziksel ve fizyolojik gereksinimleri, futbolcuların oynadıkları mevkilere göre değerlendirilmeleri önemlidir (Güldal, 2013).

Futbolcuların bireysel performans değerlerinin yapılan testler sonucunda bilinmesi uygun antrenman programlaması için önemlidir. Bu nedenle bu çalışmanın amacı çalışmaya katılan futbolcuların Yo-Yo IR1 testlerinden formüller yardımıyla elde edilen endirekt olarak bireysel $\mathrm{VO}_{2 \text { maks }}$ tahmin değerlerinin mevkilere göre incelenmesidir. Bu sayede futbolcuların oynadıkları pozisyonların $\mathrm{VO}_{2 m a k s}$ değerleri ile ilişkili olup olmadığı araştırılacaktır.

\section{Yöntem}

\section{Evren ve Örneklem}

Araştırmanın örneklem grubunu Türkiye Futbol Federasyonu (TFF) Spor Toto Süper Lig İlhan Cavcav Sezonunda mücadele eden bir takım $(n=21)$ ile aynı takımın U21 Ligi altyapı takım $(n=21)$ oyuncularının katıldığı, toplam 42 futbolcu oluşturmaktadır.

\section{Veri Toplama Araçları}

Sporcuların tanımlayıcı verileri olarak boy ve vücut ağırlığı ölçümleri yapılmıştır.

Boy Uzunluğu: Sporcuların boy uzunlukları hassaslık derecesi $0.01 \mathrm{~m}$ olan stadiometre (Seca, Almanya) ile anatomik duruşta, çıplak ayak, ayak topukları birleşik, denek nefesini tutmuşken, baş frontal düzlemde, baş üstü tablası verteks noktasına değer şekilde pozisyon alındıktan sonra ölçülmüş ve değerler 'cm' cinsinden kaydedilmiştir. 
Vücut Ağırlığı: Sporcuların vücut ağırlığı ölçümleri hassaslık derecesi $0.01 \mathrm{~m}$ olan stadiometre (Seca, Almanya) ile sporcuların üzerinde sadece şort varken, çıplak ayak ve anatomik duruş pozisyonunda ölçülmüş ve ' $\mathrm{kg}$ ' cinsinden kaydedilmiştir. Çalışmada aerobik dayanıklılık özelliği Yo-Yo IR1 yöntemi ile gerçekleştirilmiştir.

Yo-Yo Aralıklı Toparlanma Seviye 1 Testi: Araştırmada, Bangsbo tarafından bir saha testi olarak tasarlanan Yo-Yo IR1 aralıklı toparlanma seviye 1 testi uygulanmıştır. Bu test, 10 saniyelik otomatik sinyaller ile kontrol edilen yürüme veya jog şeklindeki aktif toparlanma dönemi ile serpiştirilen, kademeli olarak artan hızlardaki $2 \times 20$ metrelik mekik koşularını içermektedir. Başlangıç çizgisinin 5 metre arkası aktif toparlanma bölgesini temsil etmektedir. Bir sporcunun gücü bitene kadar ya da iki kez bitiş çizgisine ulaşmada başarısız olduğunda ise o sporcu için test sonlandırılmıştır (Sezgin, 2011).

Deneklerin $\mathrm{VO}_{2 m a k s}$ değerleri, Yo-Yo IR1 test sonucuna göre aşağıdaki formül ile hesaplanmıştır.

Yo-Yo IR1 testi: VO 2 maks $(\mathrm{ml} / \mathrm{dk} / \mathrm{kg})=$ IR1 mesafe $(\mathrm{m}) \times 0,0084+36,4$ (Bangsbo, Laia, Krustrup, 2008).

\section{Verilerin Analizi}

Verilerin istatistiksel analizinde SPSS.21 paket programı kullanılarak, futbolcuların mevkilerine ilişkin tanımlayıcı analizleri ortalama ve standart sapma olarak hesaplanmıştır. Futbolcuların mevkilere göre $\mathrm{VO}_{2 m a k s}$ değerleri arasındaki farklar Bağımsız İki Örnek T testi ile test edilmiştir. Anlamlıık düzeyi $p<0,05$ olarak alınmıştır.

\section{Bulgular}

Tablo 1: Katılımcıların Tanımlayıcı İstatistiki Bilgileri

\begin{tabular}{|c|c|c|c|c|c|c|}
\hline & \multirow[t]{2}{*}{ Kategori } & \multirow[t]{2}{*}{$\mathbf{N}$} & \multicolumn{2}{|r|}{ Ortalama } & SS ( \pm ) & \multirow[b]{2}{*}{ Hücum } \\
\hline & & & Kaleci & Savunma & Orta Saha & \\
\hline \multirow{6}{*}{ Vücut Kütlesi (kg) } & A takım & 21 & $26,7 \pm 4,04$ & $25,7 \pm 4,46$ & $24,2 \pm 4,36$ & $22,6 \pm 2,97$ \\
\hline & U21 & 21 & $18,3 \pm 0,6$ & $18,8 \pm 0,4$ & $18,2 \pm 0,5$ & $17,7 \pm 1,26$ \\
\hline & A takım & 21 & $190,7 \pm 2,52$ & $183 \pm 4,16$ & $180,2 \pm 4,31$ & $177,8 \pm 6,1$ \\
\hline & U21 & 21 & $188 \pm 3,61$ & $177,4 \pm 6,89$ & $176,6 \pm 3,05$ & $176,2 \pm 5,91$ \\
\hline & A takım & 21 & $87,5 \pm 4,1$ & $77,4 \pm 6,75$ & $73,6 \pm 3,83$ & $78 \pm 7,1$ \\
\hline & U21 & 21 & $79,8 \pm 2,93$ & $75,4 \pm 5,32$ & $71 \pm 2,73$ & $72,9 \pm 7,98$ \\
\hline
\end{tabular}


Çalışmaya katılan toplam 42 futbolcudan A takımda oynayan 21 futbolcunun oyun pozisyonlarına göre (kaleci, savunma, orta saha ve hücum) sırasıyla yaş ortalaması: $26,7 \pm 4,04$ yıl, $25,7 \pm 4,46$ yıl, $24,2 \pm 4,36$ yıl, 22,6 $\pm 2,97$ yıl; boy uzunluğu: $190,7 \pm 2,52$ $\mathrm{cm}, 183 \pm 4,16 \mathrm{~cm}, 180,2 \pm 4,31 \mathrm{~cm}, 177,8 \pm 6,1 \mathrm{~cm}$; vücut kütlesi: $87,5 \pm 4,1 \mathrm{~kg}$, $77,4 \pm 6,75 \mathrm{~kg}, 73,6 \pm 3,83 \mathrm{~kg}, 78 \pm 7,1 \mathrm{~kg}$ olarak tespit edilmiştir. U21 takımında oynayan 21 futbolcunun oyun pozisyonlarına göre (kaleci, savunma, orta saha ve hücum) sırasıyla yaş ortalaması: 18,3 $\pm 0,6 \mathrm{yıl}, 18,8 \pm 0,4 \mathrm{yıl}, 18,2 \pm 0,5 \mathrm{yıl}, 17,7 \pm 1,26$ yıl; boy uzunluğu: $188 \pm 3,61 \mathrm{~cm}, 177,4 \pm 6,89 \mathrm{~cm}, 176,6 \pm 3,05 \mathrm{~cm}, 176,2 \pm 5,91 \mathrm{~cm}$; vücut kütlesi: $79,8 \pm 2,93 \mathrm{~kg}, 75,4 \pm 5,32 \mathrm{~kg}, 71 \pm 2,73 \mathrm{~kg}, 72,9 \pm 7,98 \mathrm{~kg}$ olarak belirlenmiştir.

Tablo 2: Katılımcıların Mevkilerine Göre VO $_{2 \text { maks }}$ Değerleri

\begin{tabular}{|c|c|c|c|c|c|c|c|c|c|}
\hline & \multicolumn{3}{|c|}{$\overline{\mathbf{N}}$} & \multicolumn{2}{|c|}{ Ortalama } & \multicolumn{2}{|c|}{ SS ( $( \pm)$} & \multirow[b]{2}{*}{$t$} & \multirow[b]{2}{*}{ p } \\
\hline & Mevki & $A$ & U21 & A & U21 & A & U21 & & \\
\hline \multirow{4}{*}{ Koşu Mesafesi } & Kaleci & 3 & 3 & 1746 & 1253 & 83,3 & 122,2 & 5,78 & $0,004^{*}$ \\
\hline & Savunma & 7 & 9 & 2525 & 1648 & 283,3 & 129,3 & 8,30 & $0,000^{*}$ \\
\hline & Orta Saha & 6 & 5 & 2600 & 1752 & 313,9 & 400 & 3,95 & $0,003^{*}$ \\
\hline & Hücum & 5 & 4 & 2368 & 1800 & 175,3 & 73 & 6,01 & $0,001^{*}$ \\
\hline \multirow{4}{*}{$\mathrm{VO}_{2 \mathrm{maks}}$} & Kaleci & 3 & 3 & 50,9 & 46,9 & 1 & 1,01 & 5,38 & $0,006^{*}$ \\
\hline & Savunma & 7 & 9 & 57,6 & 50,2 & 2,37 & 1,09 & 8,34 & 0,000 * \\
\hline & Orta Saha & 6 & 5 & 58,2 & 51,7 & 2,67 & 2,04 & 9 & $0,002^{*}$ \\
\hline & Hücum & 5 & 4 & 56,2 & 51,5 & 1,47 & 0,6 & 6,05 & $0,001^{*}$ \\
\hline
\end{tabular}

$\mathrm{VO}_{2 \text { maks: }}$ Vücudun kilogram başına tüketilen maksimum oksijen miktarı $\left(\mathrm{ml}^{\prime} \cdot \mathrm{dk}^{-1} \cdot \mathrm{kg}^{-1}\right)^{*} \mathrm{p}<0,05$

Tablo 2 incelendiğinde çalışmaya katılan A takımda oynayan futbolcuların oynadıkları mevkilere göre koşu mesafeleri sırasıyla kaleci, savunma, orta saha ve hücum pozisyonları için: $1746 \pm 83,3$ m.; $2525 \pm 283,3$ m.; $2600 \pm 313,9$ m.; $2368 \pm 175,3$ m. olarak tespit edilmiştir. Aynı takımın U21 ligi futbolcularının mevkilere göre kat ettikleri mesafe: $1253 \pm 122,2$ m.; $1648 \pm 129,3$ m.; $1752 \pm 400$ m.; $1800 \pm 73$ m. olarak belirlenmiştir.

Ayrıca bu mesafelere karşılık gelen $\mathrm{VO}_{2 \text { maks }}$ değerleri sırasıyla oynadıkları

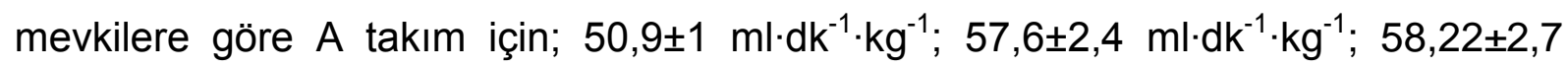
$\mathrm{ml} \cdot \mathrm{dk}^{-1} \cdot \mathrm{kg}^{-1} ; 56,2 \pm 1,47 \mathrm{ml} \cdot \mathrm{dk}^{-1} \mathrm{~kg}^{-1}$ olarak tespit edilmiştir. Aynı takımın U21 ligi futbolcularının koştukları mesafelere karşıık gelen $\mathrm{VO}_{2 \text { maks }}$ değerleri sırasıyla oynadıkları mevkilere göre: $46,9 \pm 1 \mathrm{ml} \cdot \mathrm{dk}^{-1} \cdot \mathrm{kg}^{-1} ; 50,2 \pm 1,09 \mathrm{ml} \cdot \mathrm{dk}^{-1} \cdot \mathrm{kg}^{-1} ; 51,7 \pm 2,04$ $\mathrm{ml} \cdot \mathrm{dk}^{-1} \cdot \mathrm{kg}^{-1} ; 51,5 \pm 0,6 \mathrm{ml} \cdot \mathrm{dk}^{-1} \cdot \mathrm{kg}^{-1}$ olarak belirlenmiştir. 
A takım kalecileri ile U21 takım kalecileri arasında istatistiksel anlamlı büyük fark $(p<0,05)$; A takım savunma oyuncuları ile U21 takım savunma oyuncuları arasında istatistiksel anlamlı büyük fark $(p<0,05)$; A takım orta saha oyuncuları ile U21 takım orta saha oyuncuları arasında istatistiksel anlamlı büyük fark $(p<0,05)$ ve son olarak A takım hücum oyuncuları ile U21 takım hücum oyuncuları arasında istatistiksel anlamlı büyük fark $(p<0,05)$ tespit edilmiştir.

\section{Tartışma ve Sonuç}

Türkiye Futbol Federasyonu (TFF) Spor Toto Süper Lig İlhan Cavcav Sezonunda mücadele eden bir takım ( $n=21)$ ile aynı takımın U21 Ligi altyapı takımı ( $n=21)$ oyuncularının $\mathrm{VO}_{2 m a k s}$ değerlerini belirlemek için kullanılan Yo-Yo IR1 testlerinden formüller yardımıyla elde edilen endirekt $\mathrm{VO}_{2 m a k s}$ tahmin değerlerinin futbolcuların oynadıkları pozisyonlara göre karşılaştırılması amacıyla yapılan bu çalışmaya 42 profesyonel futbolcu katılmıştır. Çalışmaya katılan toplam 42 futbolcudan A takımda oynayan 21 futbolcunun oyun pozisyonlarına göre (kaleci, savunma, orta saha ve hücum) sırasıyla yaş ortalaması: $26,7 \pm 4,04$ yıl, 25,7 $\pm 4,46$ yıl, 24,2 $\pm 4,36$ yıl, 22,6 $\pm 2,97$ yıl; boy uzunluğu: $190,7 \pm 2,52 \mathrm{~cm}, 183 \pm 4,16 \mathrm{~cm}$, $180,2 \pm 4,31 \mathrm{~cm}, 177,8 \pm 6,1 \mathrm{~cm}$; vücut kütlesi: $87,5 \pm 4,1 \mathrm{~kg}, 77,4 \pm 6,75 \mathrm{~kg}, 73,6 \pm 3,83$ $\mathrm{kg}, 78 \pm 7,1 \mathrm{~kg}$ olarak tespit edilmiştir. U21 takımında oynayan 21 futbolcunun oyun pozisyonlarına göre (kaleci, savunma, orta saha ve hücum) sırasıyla yaş ortalaması: $18,3 \pm 0,6 \mathrm{yll}, 18,8 \pm 0,4 \mathrm{yıl}, 18,2 \pm 0,5 \mathrm{yıl}, 17,7 \pm 1,26 \mathrm{yll}$; boy uzunluğu: $188 \pm 3,61 \mathrm{~cm}$, $177,4 \pm 6,89 \mathrm{~cm}, 176,6 \pm 3,05 \mathrm{~cm}, 176,2 \pm 5,91 \mathrm{~cm}$; vücut kütlesi: 79,8 $\pm 2,93 \mathrm{~kg}$, $75,4 \pm 5,32 \mathrm{~kg}, 71 \pm 2,73 \mathrm{~kg}, 72,9 \pm 7,98 \mathrm{~kg}$ olarak belirlenmiştir.

Yo-Yo IR1 testlerinin farklı spor branşlarında, mücadele seviyelerinde ve farklı oyun pozisyonlarında oynayan sporcular arasındaki farklılıklar ile birlikte fiziksel kapasitenin dönemsel ya da sezon boyunca değişiklikler arasındaki farklılıkları belirlemede geçerli ve hassas bir test olduğu ileri sürülebilir (Can ve diğerleri, 2011). A takım futbolcularının oynadıkları oyun pozisyonlarına göre değerlendirildiğinde oyuncuların Yo-Yo IR1 testinde kaleci, savunma, orta saha ve hücum olmak üzere

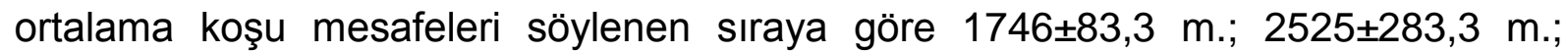
$2600 \pm 313,9$ m.; 2368 $\pm 175,3 \mathrm{~m}$. olarak elde edilmiştir. U21 takım futbolcularının oynadıkları oyun pozisyonlarına göre değerlendirildiğinde ise oyuncuların Yo-Yo IR1 testinde kaleci, savunma, orta saha ve hücum olmak üzere ortalama koşu mesafeleri

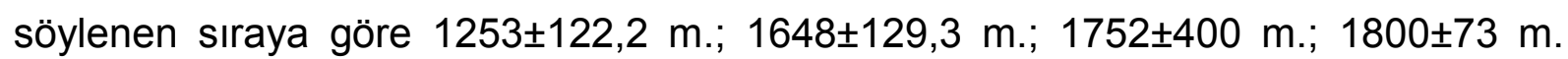


olarak tespit edilmiştir. Yapılan bir çalışmada Yo-Yo IR1 testinde elde edilen veriler doğrultusunda uluslararası seviyede futbol oynayan en üst düzeydeki erkek futbolcuların $3420 \mathrm{~m}$, orta derecede antrenman yapan futbolcuların $2810 \mathrm{~m}$, alt seviyedeki oyuncuların 2330 m ve çok düşük bir seviyede oynayan diğer oyuncuların 2190 m koşu mesafesine sahip oldukları bildirilmiştir (Castagna ve diğerleri, 2006). İtalya ve Danimarka liginde oynayan futbolcularla yapılan bir çalışmada ise savunma, orta saha, hücum oyuncuları için söylenen sıraya göre, 2210 m., 2230 m. ve 1990 m. ortalama Yo-Yo IR1 koşu mesafesi rapor edilmiştir (Mohr, Krustrup, Bangsbo, 2003). Daha önce yapılmış Yo-Yo IR1 testinden elde edilen veriler doğrultusunda futbolculardan en fazla mesafenin savunma $(1968 \mathrm{~m})$ ve orta saha $(1774 \mathrm{~m})$, en düşük mesafenin ise hücum $(1662 \mathrm{~m})$ oyuncuları tarafından koşulduğu tespit edilmiştir (Can ve diğerleri, 2011). Yüksek düzeyde performansa sahip profesyonel futbolcuların katıldığı diğer bir çalışmada ise futbolcular tarafından koşulan en fazla mesafenin orta saha (1987 m) ve savunma oyuncularına (1925 m) ait olduğu, hücum oyuncularının $(1744 \mathrm{~m})$ ve kalecilerin $(1266 \mathrm{~m})$ ise koşu mesafelerinin diğer mevkilerde ki oyunculara göre düşük ortalama değerlerine sahip oldukları bildirilmiştir (Cihan, Can ve Seyis, 2012). Futbolcuların oynadıkları mevkilere göre savunma ve orta saha oyuncularının, kaleci ve hücum pozisyonunda oynayan diğer futbolculara göre daha fazla koşu mesafesine sahip oldukları literatürde daha önce yapılmış çalışmalarla benzerlik göstermektedir (Krustup ve diğerleri, 2006). Yo-Yo IR1 testinin kullanıldığı ve 69 futbolcu ile yapılan bir başka çalışmada ise savunma oyuncularının ( $n=29) 2469 \pm 627$ m., orta saha oyuncularının $(n=30) 2529 \pm 736$ m., hücum oyuncularının $(n=10) 2288 \pm 639 \mathrm{~m}$. koşu mesafelerini ve bu mevkiler arasında anlamlı bir farklılığın olmadığını tespit etmişlerdir (Malina ve diğerleri, 2004).

Çalışmaya katılan futbolcuların Yo-Yo IR1 testi ile koşu mesafeleri hesaplanarak elde edilen veriler doğrultusunda mevkilere göre bireysel $\mathrm{VO}_{2 m a k s}$ değerleri belirlenmiştir. A takım futbolcularının oynadıkları oyun pozisyonlarına göre ortalama $\mathrm{VO}_{2 \text { maks }}$ değerleri kaleciler için, $50,9 \pm 1 \mathrm{ml} \cdot \mathrm{dk}^{-1} \cdot \mathrm{kg}^{-1}$ savunma oyuncuları için $57,6 \pm 2,37 \mathrm{ml} \cdot \mathrm{dk}^{-1} \cdot \mathrm{kg}^{-1}$, orta saha oyuncuları için $58,2 \pm 2,67 \mathrm{ml} \cdot \mathrm{dk}^{-1} \cdot \mathrm{kg}^{-1}$ ve hücum oyuncuları için ise $56,2 \pm 1,47 \mathrm{ml} \cdot \mathrm{dk}^{-1} \cdot \mathrm{kg}^{-1}$ olarak elde edilmiştir. U21 takımı futbolcularının ise oynadıkları oyun pozisyonlarına göre ortalama $\mathrm{VO}_{2 m a k s}$ değerleri

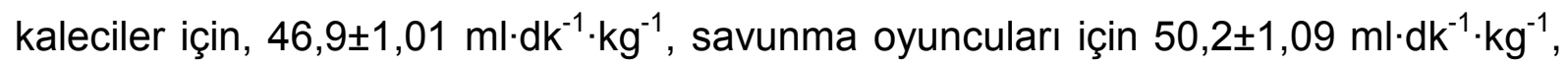
orta saha oyuncuları için $51,7 \pm 2,04 \mathrm{ml} \cdot \mathrm{dk}^{-1} \cdot \mathrm{kg}^{-1}$ ve hücum oyuncuları için ise $51,5 \pm 0,6 \mathrm{ml} \cdot \mathrm{dk}^{-1} \cdot \mathrm{kg}^{-1}$ olarak belirlenmiştir. A takım oyuncuları ile U21 takımı 
oyuncularının mevkilere göre karşılaştıııması sonucunda sırasıyla (kaleciler için $p<0,05$; savunma oyuncuları için $p<0,05$; orta saha oyuncuları için $p<0,05$; hücum oyuncuları için $p<0,05)$ tüm mevkilerde anlamlı büyük fark tespit edilmiştir $(p<0,05)$. Literatür incelendiğinde, Bangsbo, Danimarkalı profesyonel futbolcular ile yaptığı çalışmasında orta sahada mücadele eden futbolcuların ortalama $\mathrm{VO}_{2 m a k s}$ değerlerini $62,6 \mathrm{ml} \cdot \mathrm{dk}^{-1} \cdot \mathrm{kg}^{-1}$ olarak tespit etmiştir (Bangsbo, 1994). Reevess ve arkadaşlarının yapmış oldukları çalışmada ise savunmada mücadele eden futbolcuların ortalama $\mathrm{VO}_{2 \text { maks }}$ değerlerini $54,4 \mathrm{ml} \cdot \mathrm{dk}^{-1} \cdot \mathrm{kg}^{-1}$, orta saha oyuncularının $42,8 \mathrm{ml} \cdot \mathrm{dk}^{-1} \cdot \mathrm{kg}^{-1}$ ve hücum oyuncularının ise $50,7 \mathrm{ml} \cdot \mathrm{dk}^{-1} \cdot \mathrm{kg}^{-1}$ olarak bildirmişlerdir (Reevess ve diğerleri, 1999) . Ayrıca Al'Hazzaa ve arkadaşları savunma mevkiinde görev alan oyuncuların $52,3 \mathrm{ml} \cdot \mathrm{dk}^{-1} \cdot \mathrm{kg}^{-1}$ orta saha oyuncularının $59,9 \mathrm{ml} \cdot \mathrm{dk}^{-1} \cdot \mathrm{kg}^{-1}$, hücum pozisyonunda $\mathrm{ki}$ oyuncuların ise $56,9 \mathrm{ml} \cdot \mathrm{dk}^{-1} \cdot \mathrm{kg}^{-1}$ ortalama $\mathrm{VO}_{2 \text { maks }}$ değerlerine sahip oldukların belirtmişlerdir (Al'Hazzaa ve diğerleri, 2001). Yapılan bir çalışmanın sonuçlarına göre; orta saha oyuncularının koşu mesafesine karşılık gelen $\mathrm{VO}_{2 \text { maks }}$ değerlerinin $53 \pm 2,17$ $\mathrm{ml} \cdot \mathrm{dk}^{-1} \cdot \mathrm{kg}^{-1}$ diğer oyun pozisyonlarındaki oyunculardan daha yüksek olduğu tespit edilmiştir. Sonuç olarak, elit seviyedeki erkek futbolcuların aerobik güç performansları ve toparlanma sürelerinin futboldaki oyun pozisyonlarına göre farklılaştığı istatistiksel olarak elde edilmiştir (Cihan, Can, Seyis, 2012). Bir oyuncunun takım içindeki rolünün onun fizyolojik kapasitesi ile bağlantılı olduğunu belirterek orta saha oyuncularının

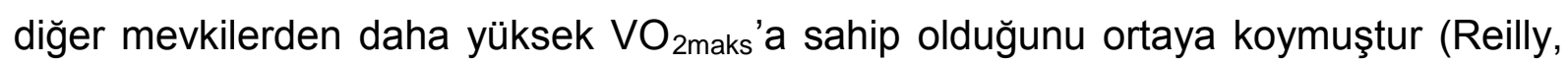
Bangsbo ve Franks 2000). Krustrup ve ark. ise kalecilerin ve hücum oyuncularının diğer mevkilerde anlamlı şekilde düşük aerobik kapasiteye sahip olduğu bildirmişlerdir (Krustrup ve diğerleri, 2006).

Literatür incelemeleri sonucunda daha önce yapılmış olan çalışmalarda elde edilen verilerin, bu çalışmada A ve U21 takımlarından elde edilen değerlerle benzerlik gösterdiğini fakat bazı mevkilerde elde edilen verilerin farklılık gösterdiği belirlenmiştir. Bu farkııı̆ın futbolcuların oynadıkları pozisyonlardan kaynaklandığını ve müsabaka sırasında futbolcuların kendi görev bölgesinde ki sorumluluklarının artmasının oyun içerisindeki bireysel performanslarını belirlemede önemli bir etken olduğu düşünülmektedir. Savunma ve orta saha mevkilerinde görev alan futbolcuların sorumluluklarının daha geniş bir alanı kontrol etmek olduğu için başarılı bir performans sergilemeleri daha fazla efor gerektirir. Bu yüzden bu mevkilerde oynayan futbolcuların koşu mesafelerinin ve $\mathrm{VO}_{2 \text { maks }}$ değerlerinin diğer mevkilere göre yüksek olması, bu çalışmada elde edilen verileri destekler niteliktedir. 
Sonuç olarak profesyonel futbolcuların aerobik güç performans değerlerinin oynadıkları mevkilere göre farklılık gösterebileceği ortaya konulmuştur. Antrenörlerin bu farklııkları bilmesi ve buna uygun antrenman programı hazırlaması, oyuncularının antrenmanlarda ve müsabakalarda performanslarında bir artışı beraberinde getirebileceği düşünülebilir.

\section{Kaynaklar}

Ak M. (2010).Türkiye Ve Azerbaycan Futbol Liglerinde Mücadele Eden U15 U16 U17 Takım Futbolcularının Aerobik Güç Performansının Karşılaştırıması, Selçuk Üniversitesi Sağlık Bilimleri Enstitüsü, Yüksek Lisans Tezi, Konya.

Al'Hazzaa, M. H., Almuzaini, S. K. Al-Rafaee, A. S., Sulaiman, M. A., Dafterdar, Y. M., Al-Ghamedi, A., Al- Khuraiji, N. K., (2001). Aerobic and Anaerobic Power Characteristic of Saudi Elite Soccer Players" J. Sports Med. Phys Fitness. 41(1), 54-61.

Aşçı, A. (2008). Futbol Eğitimi 14 Yaş ve Altı. Neyir Matbaacılık. Tüvaf Yayınları, (1), 34-37

Bangsbo J, Norregaard L, Thorsoe F. (1991). Activity Profile Of Competition Soccer. Canadian Journal of Sports Science, (16), 110-116.

Bangsbo, J., (1994). The Physiology of Soccer with Special Reference to Intense Intermittent Exercise Acta Physiol. Scand. 619 1-155.

Bangsbo, J., Laia, F. M., Krustrup, P. (2008). The Yo-Yo Intermittent Recovery Test, A Useful Tool for Evaluation of Physical Performance in Intermittent Sport, Sports Medicine, 38(1), 37-51.

Can I., Cihan H., (2013). Yo-Yo Aralıkı Toparlanma Testleri Ve Sportif Performans Üzerine Genel Bir Değerlendirme, Ankara Üniversitesi Spor Bilimleri Fakültesi, 11(2), 81-94.

Can, İ., Cihan, H., Doğan, A.A., Arı, E., Aka, S.T., İmamoğlu, R. (2011). The Comparison of the Aerobic Power Capacities of Male Amateur Football Players Competed in Different Playing Positions in Turkey", Report Series Physical Education and Sport, 15(1), 186-190.

Castagna, C., Chamari, K., Impellizzerri, M.F., Carlomogno, D. (2006). Aerobic Fitness and Yo-Yo Continuous and Intermittent Tests Performances in Soccer Players: Acarrelation Study, The Journal of Strength and Conditioning Research, 20(2). 
Castagna, C., Impellizzeri, F.M., Cecchini, E., Rampinini, E., \& Barbero-Álvarez, C.J. (2009). Effects Of İntermittent-Endurance Fitness On Match Performance İn Young Male Soccer Players, J Strength Cond Res., 23(7), 1954-1959.

Castagna, C., Manzi, V., Impellizzeri, F., Weston, M., \& Alvarez, J. C. B. (2010). Relationship Between Endurance Field Tests And Match Performance İn Young Soccer Players. The Journal of Strength \& Conditioning Research, 24(12), 3227-3233.

Chamari, K., Hachana, Y., Ahmed, B. Y., Galy, O.,Sghaier, F., Chatard, J. C., Hue, O., Wisloff, U. (2004). Field andLaboratory in Young Elite Soccer Players, Br. J. Sports Medicine. 38, 191-196.

Cihan H., Can İ., Seyis M. (2012). Comparıson Of Recoverıng Tımes And Aerobıc Capacıty Accordıng To Playıng Posıtıons Of Elıte Football Players, Nigde University Journal of Physical Education And Sport Sciences 6(1).

Ek, R.O., Temoçin, S., Tekin, A.T., Yıldız, Y. (2007). Futbolculara Uygulanan Bazı Motorsal Egzersizlerin Birbirlerine Etkilerinin İncelenmesi, ADÜ Tıp Fakültesi Dergisi, 8(1).

Güldal, Y.K. (2013). Profesyonel Futbolcularda Aerobik ve Anaerobik Kapasite İlişkisinin Oyuncuların Mevkilerine Göre İncelenmesi, Yüksek Lisans Tezi, Kırıkkale Üniversitesi Sağlık Bilimleri Enstitüsü Hareket ve Antrenman Bilimleri Anabilim Dalı, Kırıkkale.

Krustrup, P, Mohr, M, Nybo, L, Majgaard Jensen, J, Jung Nielsen, J, and Bangsbo, J. (2003). The Yo-Yo İntermittent Recovery Test: Physiological Response, Reliability, And Validity. Med Sci Sports Exerc 35, 697-705.

Krustrup, P., Mohr, M., Nybo, L., Majgaard, J. J., Jung N.J., Bangsbo, J. (2006). The Yo-Yo IR2 Test: Physiological Response, Reliability, and Application to Elite Soccer. Med. Sci. Sports Exerc., 38( 9), 1666-1673.

Malina, R.M., Eisenmann, J.C., Cumming, S. P., Ribeiro, B. and Aroso, J. (2004) Maturity-Associated Variation In The Growth And Functional Capacities Of Youth Football (Soccer) Players 13-15 Years. European Journal of Applied Physiology 91, 555- 562.

Mohr, M., Krustrup, P., Bangsbo, J. (2003). Match Performance of High Standart Soccer Players with Special Reference to Development of Fatigue, Journal of Sports Sciences, 21(7), 519-528. 
Reevess, S. L., Poh, B. K., Brown, M., Tizzard, N. H., Ismail, M. N. (1999). Anthropometric Measurement and Body Composition of Englishand Malaysian Footballers, Malaysian Journal of Nutrition. 5, 79-86.

Reilly, T., Bangsbo, J., Franks, A. (2000). Anthropometric And Physiological Predispositions For Elite Soccer. Journal of Sports Sciences, 18, 669- 683.

Sezgin, E. (2011). Bayan Futbolcuların Oyun Pozisyonlarına Göre Aerobik Güç Performanslarının ve Toparlanma Süreçlerinin Karşılaştırılması, Yüksek Lisans Tezi, Karadeniz Teknik Üniversitesi Eğitim Bilimleri Enstitüsü Beden Eğitimi ve Spor Anabilim Dalı, Trabzon.

Svensson, M., Drust, B. (2005). Testing Soccer Players" Journal of Sports Sciences, 23(6), 601-618.

Ünal M, Kayserilioğlu A, Kaşıkçıŏlu F, Yıldız S, Bekar Ö, Yılmaz P. (2001). 16-38 Yaş Grubu Profesyonel Erkek ve Bayan Futbolcuların Metabolik ve Efor Testleri Sonuçlarının Karşılaştırılması, İstanbul, Spor ve Tıp Dergisi. 